\title{
Tumor-Suppressing Effect of MiR-4458 on Human Hepatocellular Carcinoma
}

\author{
Dan Tang ${ }^{\mathrm{a}}$ Baomu Sun ${ }^{\mathrm{b}}$ Hongyu Yu ${ }^{\mathrm{d}}$ Zhengde Yang ${ }^{\mathrm{a}}$ Liang Zhu ${ }^{\mathrm{c}}$ \\ aDepartment of Gastroenterology, Chinese PLA 89 Hospital, Weifang, ${ }^{\text {bDepartment }}$ of Integrated \\ Chinese Traditional and Western Medicine, Eastern Hepatobiliary Surgical Hospital, Second Military \\ Medical University, Shanghai, 'Department of Gastroenterology, Changzheng Hospital, Second Military \\ Medical University, Shanghai, dDepartment of Pathology, Changzheng Hospital, Second Military \\ Medical University, Shanghai, China
}

\author{
Key Words \\ Hepatocellular carcinoma • Apoptosis • Micro-RNAs
}

\begin{abstract}
Background: Besides multiple genetic and epigenetic changes of protein coding genes in hepatocellular carcinoma (HCC), growing evidence indicate that deregulation of miRNAs contribute to HCC development by influencing cell growth, apoptosis, migration, or invasion. $I K B K E$ is amplified and over-expressed in a large percentage of human breast tumors and identified as an oncogene of human breast tumor. Microarray analysis showed that miR-4458 was down-regulated in HCC tissues. Methods: The level of miR-4458 was up-regulated by miR4458 mimics transfection, or down-regulated by miR-4458 ASO transfection. Cell proliferation was assayed by MTT analysis. MiRNAs and mRNA expression were assayed by qRT-PCR. These potential targeted genes of miR-4458 were predicted by bioinformatic algorithms. Dual luciferase reporter assay system was used to analyze the interaction between miR-4458 and IKBKE. IKBKE protein level was assayed by Western blot. The role of miR-4458 or IKBKE in the survival of HCC patients were revealed by Kaplan-Meier plot of overall survival. Results: Lower miR-4458 expression level or higher IKBKE level in HCC tissues correlated with worse prognosis of HCC patients. Overexpression of miR-4458 inhibited the HCC cells growth and vice versa. MiR-4458 played its role via targeting 3'UTR of IKBKE. Conclusions: MiR-4458 or IKBKE may be potential predictors of HCC prognosis. Restoration of miR-4458 or inhibition of IKBKE could be a prospective therapeutic approach for HCC.
\end{abstract}

D. Tang and B. Sun contributed equally to this work.

Liang Zhu and Zhengde Yang

KARGER 125
Department of Gastroenterology, Shanghai Changzheng Hospital, Second Military Medical University, 415 Fengyang Road, Shanghai 200003 (China) and Department of Gastroenterology, Chinese PLA 89 Hospital, Weifang, Shandong Province (China) E-Mail CZZHULIANG2013@126.com and E-Mail 13792670038@163.com 


\section{Cellular Physiology Cell Physiol Biochem 2015;35:1797-1807

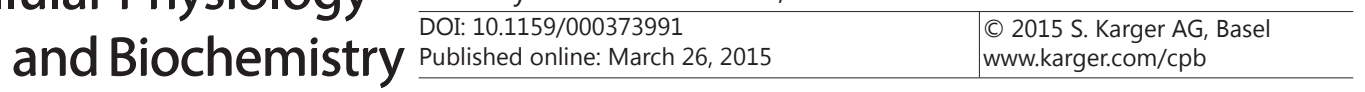

Tang et al.: MiR-4458 on HCC

\section{Introduction}

Hepatocellular carcinoma (HCC) is one of the leading causes for cancer-related death [1]. Although HCC is the sixth most common neoplasm worldwide, poor prognosis makes HCC the third leading cause of cancer-related mortality, responsible for 600,000 deaths annually [2]. In some countries, especially in China, HCC accounted for 70\%-85\% of primary liver cancer cases [3], with the burden of disease expected to increase in coming years [4]. Besides multiple genetic and epigenetic changes of protein coding genes in HCC [5], growing evidence indicates that deregulation of miRNAs can also contribute to HCC development by influencing cell growth, apoptosis, migration, or invasion [6-22]. Thus, more extensive investigations are needed to identify miRNAs which can be employed as prognosis predictor or therapeutic target for HCC.

Previous study had proved that the human cells can be transformed by the cooperation of activated ERK and signaling pathway of PI3K (phosophatidylinositol 3-kinase) [23]. PI3K signaling can be replaced by various kinases, which can render cell tumorigenic. IKBKE (Inhibitor of nuclear factor kappa-B kinase subunit epsilon also known as I-kappa-B kinase epsilon) was found to be amplified and over expressed in breast carcinoma cell lines and patient-derived tumors [23].

Algorithms predicted that miR-4458 could bind the 3' UTR of IKBKE, thus we guessed that miR-4458 may play a role in the pathogenesis of HCC. Here, the functions of miR-4458 and its underlying mechanisms in HCC development were investigated. We found that HCC patients with worse prognosis correlated with the lower level of miR-4458 in HCC tissues. Furthermore, the cell growth of HCC cell lines would be suppressed if we restored miR-4458 expression. IKBKE was confirmed as the target of miR-4458. Therefore, our finding indicated that miR-4458 is a new prognosis predictor for HCC patients and a new potential therapeutic target for HCC.

\section{Materials and Methods}

\section{Human Tissue Specimens}

Liver tissue samples were obtained from patients undergoing resection from Eastern Hepatobiliary Surgery Hospital (Shanghai, China) [24]. Tissue samples were frozen immediately in liquid nitorgen until analysis. Normal human liver tissues were obtained from distal normal liver tissue of liver hemagioma. Tissue samples and matched control were achieved from HCC patients. The study was performed according the Declaration of Helsinki. All patients provided written informed consent. And the study was approved by the Ethics Committee of Second Military Medical University, Shanghai, China. All patients clinical data were recorded by electronic file and we followed the patients status more than 3 years.

\section{Cell Lines and reagent}

Huh7 cell line and Normal human hepatic cell line L-02 were maintained in RPMI1640 with 10\% FBS (PAA Laboratories, Pasching, Australia). Human HCC cell lines HepG2, Hep3B, SMMC-7721, Huh7 and Normal human hepatic cell line Chang were maintained in DMEM with 10\% FBS (PAA Laboratories, Pasching, Australia). All cell lines were obtained from the Cell Bank of Chinese Academy of Science (Shanghai, China). 5-fluorouracil (5-FU) was purchased from Shenggong company (Shanghai, China). The concentration of 5 -FU used here is $0.5 \mu \mathrm{g} / \mathrm{ml}$.

\section{RNA quantification}

Expression of miR-4458 was detected with miRCURY LNA Universal RT microRNA PCR kit (Exiqon, Boston) based on the manufacturer's instructions. MicroRNAs quantification was normalized to U6 small nuclear RNA.

MiRNAs targets were predicted using the algorithms TargetSan (https://www.targetscan.org) [29], miRand(http://www.cbio.mskcc.org/mirnaviewer) [25], PicTar (http://pictar.mdc-berlin.de) [30], miRGen 


\section{Cellular Physiology Cell Physiol Biochem 2015;35:1797-1807 \begin{tabular}{ll|l} 
and Biochemistry & $\begin{array}{l}\text { DOI: 10.1159/000373991 } \\
\text { Publisned onmIne: IVarch 26, } 2015\end{array}$ & $\begin{array}{l}\text { c 2015 S. Karger AG, Basel } \\
\text { www.karger.com/cpb }\end{array}$ \\
\hline
\end{tabular}}

Tang et al.: MiR-4458 on HCC

[31, 32] and miRBase (http://www.mirbase.org) [33]. The algorithm produces hundreds of target genes for miRNAs by searching for the presence of conserved 8-mer and 7-mer sites matching the seed region of miRNAs.

MiRNAs mimics, MiRNAs antisense oligonucleotides and overexpression plasmid

MiR-4458 mimics and miR-4458 antisense oligonucleotides (ASO) were obtained from GenePharma (GenePharma, China). Following the manufacturer's instructions, miRNAs mimics, negative control (NC) were transfected into cells at $50 \mathrm{nM}$ concentration with Lipofectamine ${ }^{\circledR} 2000$ transfection reagent. 48 $\mathrm{h}$, or $72 \mathrm{~h}$ later cells were used for further experiments. The overexpression plasmid (pBabe-Neo-Flag$I K B K E$ ) and the knock siNRA (si-IKBKE) were constructed and confirmed by Shengong Company(Shanghai) according to previous paper[23,34].

MTT assay

For MTT assay, we cultured $5 \times 10^{3}$ cells per well in a triplicate using a 96 well plate with complete growth medium. We counted the cells over 5 days with the MTT assay (Promega, Fitchburg, WI, USA) as described previously[35, 36].

Apoptosis assay

After different treatments, cells were marked with Annexin V-FITC and PI (propidium iodide) using an apoptosis detecting kit (Invitrogen, Canada) as described previously[37]. Samples were determined by FACS assays and the results were analyzed using CellQuest software (Becton Dickinson, San Jose, CA) [38].

Luciferase Reporter Assay

The 3' UTR fragments of IKBKE containing putative binding sites for miR-4458 were cloned into pMIRReport construct (Ambion, Austin, TX). The primers were synthesized by Shenggong company (Shanghai, China) according to the method as detailed elsewhere $[39,40]$. And the detail information were showed in previous paper [40]. The complementary site of miR-4458 carried a mutated sequence in the seed region, mutant 3' UTR of IKBKE, were generated using fusion PCR. As described previously, luciferase reporter assay was performed in Huh-7 cells [24].

Soft Agar Assay for Colony Formation

Growth of cells in soft agar was determined by $5 \times 10^{4}$ cells in triplicate in $0.4 \%$ (HEK) or $0.3 \%$ (HMEC) Noble agar. After 8 weeks of plating, colonies greater than $100 \mu \mathrm{m}$ in diameter were counted by microscope. Colonies greater than $200 \mathrm{~nm}$ in diameter were counted macroscopically 8 weeks after planting [23].

Survival-based tissue microarray of HCC

Survival-based tissue microarray of HCC were provided by Jianhua Yin [41]. Tissue microarray were processed and analyzed by Xinchao company (Shanghai, China).

Statistical analysis

Data is presented as the mean \pm SD from at least three independent experiments. The difference between groups was analyzed using two-tailed Student's $t$ test when only two groups were compared. The difference between groups was analyzed using ANOVA when three or more than three groups were compared. The Wilcoxon matched-pairs signed rank test was used to determine if there was a statistically significant difference in the expression of miR-4458 or IKBKE between matched pairs. Correlation analysis was performed by two-tailed Person's correlation coefficient analysis. Overall survival of patients was estimated by the Kaplan-Meier method. Statistical analysis was performed using SPSS software (version 16.0). $P<0.05$ was considered significantly different.

\section{Results}

Lower miR-4458 expression level in HCC tissues correlated with worse prognosis of HCC patients

Expression of miR-4458 in HCC cell lines were assayed by qRT-PCR. As comparing with normal liver, miR-4458 expression in HepG2, Hep3B, SMMC-7721 Huh-7 and Chang is lower. (Fig. 1A). 30 human hepatocellular carcinoma tissues were collected. Expression 


\section{Cellular Physiology and Biochemistry}

Cell Physiol Biochem 2015;35:1797-1807

Fig. 1. MiR-4458 expression in HCC and HCC patient survival analysis according to $\mathrm{miR}-4458$. A,miR-4458 expression in normal liver, L-02, HepG2, Chang, Hep3B, SMMC-7721 and Huh-7 were assayed by qRT-PCR. MiR-4458 quantification were normalized to U6 small nuclear RNA. The miR4458 expression in normal liver was arbitrary defined as $100 \%$. Data was the mean \pm SD of three independent test. B, 30 human hepatocellular carcinoma tissues and their paired normal tissues were assayed for miR-4458 expression by qRT-PCR. miR-4458 quantification were normalized to U6 small nuclear RNA. The miR4458 expression in normal liver was arbitrary defined as $100 \%$. Data was the mean \pm SD of 30 samples. C, miR-4458 expression in 30 human hepatocellular carcinoma tissues and in their matched normal tissues were compared by qRT-PCR. miR-4458 quantification were normalized to U6 small nuclear RNA. Data was the mean \pm SD of three independent test for each sample. D, Kaplan-Meier plot of overall survival in HCC patient post-operation according the expression of miR-4458. MiR-4458 median value of all 30 cases was

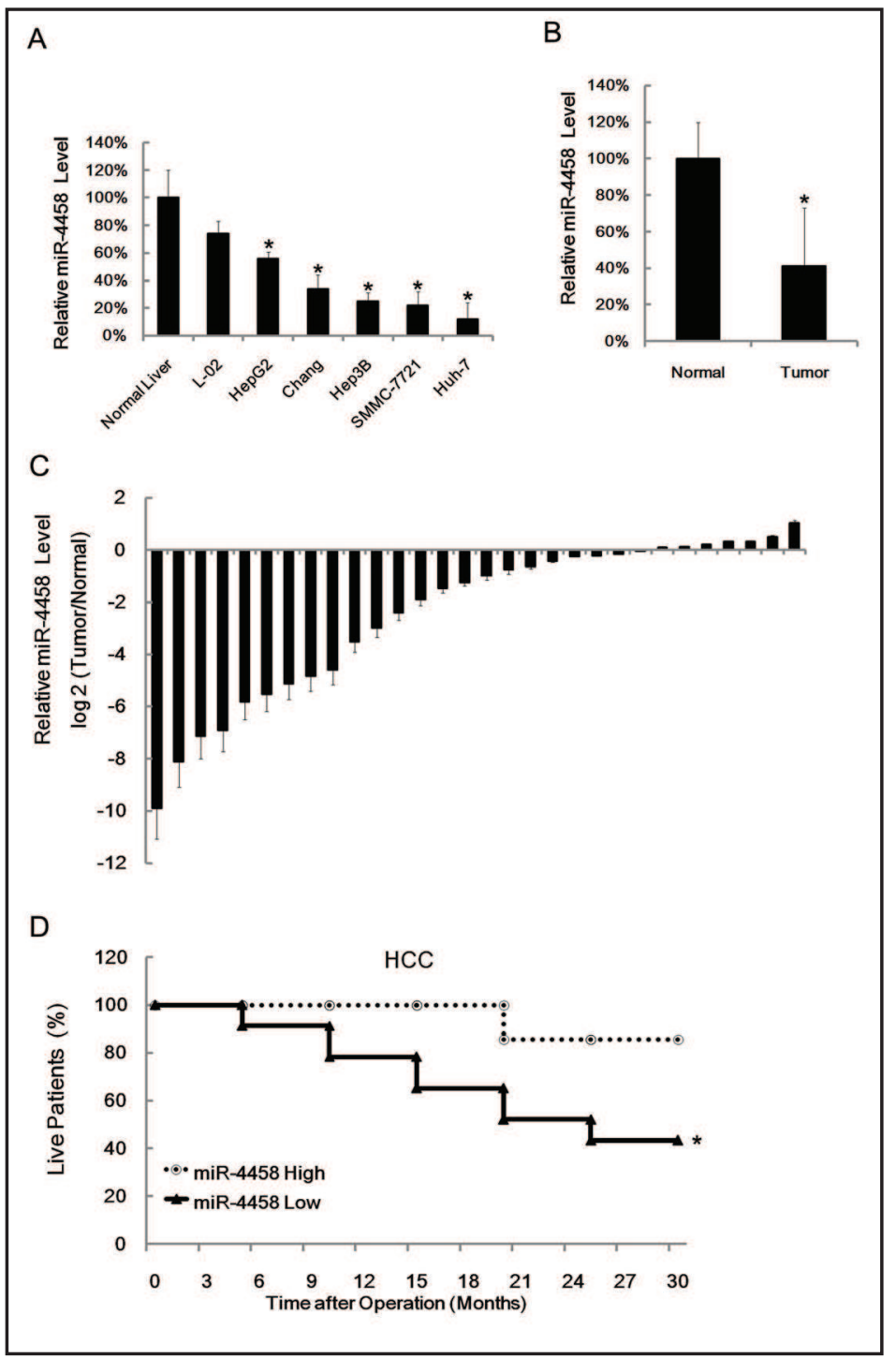
chosen as the cutoff point for separating miR-4458 high expression tumors $(n=15)$ from miR-4458 low expression cases $(n=15)$. ${ }^{*} \mathrm{P}<0.05$.

of miR-4458 in 30 human hepatocellular carcinoma tissues were assayed. We found that the average expression of miR-4458 in HCC tissues was lower than paired normal human liver tissues (Fig. 1B). In the $30 \mathrm{HCC}$ specimens, there were 23 specimens, in which the miR4458 expression is lower than matched normal tissues (Fig. 1C). To evaluate the clinical significance of miR-4458 in HCC, we investigated whether the level of miR-4458 expression was associated with overall survival in HCC patients. 30 HCC patients have been followedup for 30 months. During follow-up period, 11 out of $30(35 \%)$ patients died as a result of disease progression. Survival curve showed that patient with high miR-4458 level (15 case) had a significantly longer overall survival than those with low miR-4458 level (15 case) (Fig. 1D).

MiR-4458 inhibited the HCC cells viability in vitro

For studying the role of miR-4458 in HCC, miR-4458 in SMMC-7721 and Huh-7 were over-expressed by miR-4458 mimics, and confirmed by qRT-PCR $48 \mathrm{~h}$ or $72 \mathrm{~h}$ after mimics transfection (Fig. 2A). To investigate the role of miR-4458 in cell proliferation, MTT assay 


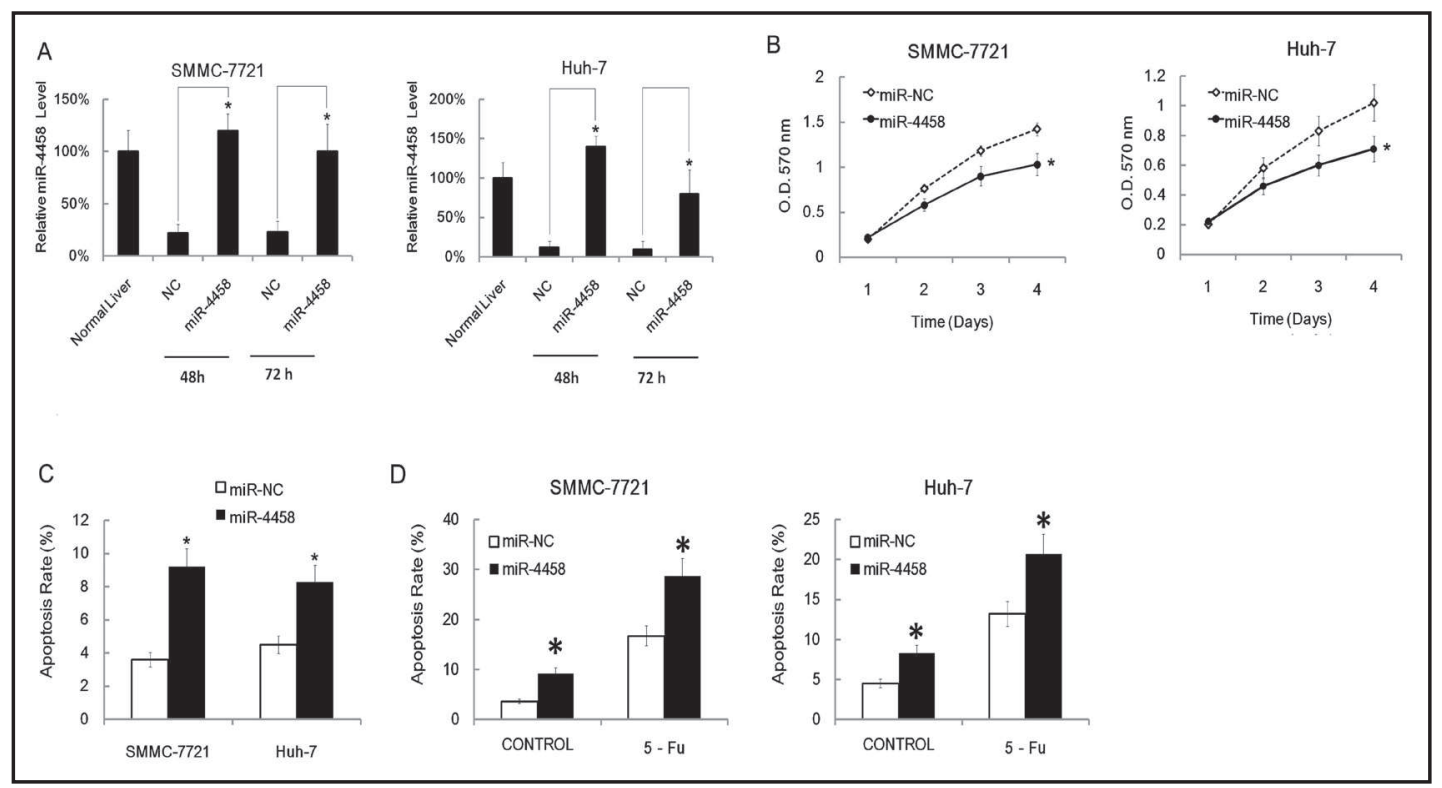

Fig. 2. MiR-4458 mimics inhibited SMMC-7721 and Huh-7 cells proliferation. A, SMMC-7721 and Huh-7 cells $\left(5 \times 10^{5}\right.$ cells/well) were transfected with miR-4458 mimics or miR-NC (NC) separately. $48 \mathrm{~h}$ or $72 \mathrm{~h}$ later, the miR-4458 expression was assayed by qRT-PCR. Data were normalized to U6 small nuclear RNA. The miR-4458 expression in normal liver tissue were arbitrarily defined as $100 \%$. Data are mean \pm SD of three separate independent sample. B, After the miR-4458 mimics transfection, the cell proliferation were assayed by MTT at the indicted time points (from 1 to 4 hours after transfection ). Data are mean \pm SD of three independent sample assays. C, After $48 \mathrm{~h}$ miR-4458 mimics transfection, the cell apoptosis rate of SMMC-7721 and Huh-7 cells was assayed by FACS. D, Following miR-4458 mimics transfection, SMMC-7721 and Huh-7 cells were treated 5-Fu $(0.5 \mu \mathrm{g} / \mathrm{ml}) .48 \mathrm{~h}$ later, the cell apoptosis rate of SMMC-7721 and Huh-7 cells was assayed by FACS analysis. Data are mean \pm SD of three separate assays*, $\mathrm{P}<0.05$.

was performed, and results showed that up-regulation of miR-4458 in SMMC-7721 and Huh7 inhibited cells proliferation (Fig. 2B). Cell apoptosis assay showed that miR-4458 induced more cell apoptosis in SMMC-7721 and Huh-7 (Fig. 2C). Besides, SMMC-7721 and Huh-7 were pretreated with $5-\mathrm{Fu}$, then the cell apoptosis was analyzed, we found that, still, miR4458 induced more cell apoptosis under the treatment of 5-Fu (Fig. 2D).

\section{Down-regulation of miR-4458 promoted cells proliferation}

As miR-4458 expression in L-02 and HepG2 cell lines were higher than other cell lines, we down-regulated the miR- 4458 expression by transfection of miR- 4458 ASO. We found that miR-4458 ASO transfection down-regulated the miR-4458 level to $40 \%$ level of control (Fig. $3 \mathrm{~A}$ ). Then, cell proliferation were assayed by MTT, we found that miR-4458 ASO promoted cell proliferation as expected (Fig. 3B). Next, Cell apoptosis assay showed that miR-4458 ASO inhibited cell apoptosis in L-02 and HepG2 cell lines than control (Fig. 3C). Similarly, L-02 and HepG2 cell were pretreated with 5-Fu, then the cell apoptosis was analyzed, we found that, still, miR-4458 ASO inhibited cell apoptosis under the pretreatment of 5-Fu (Fig. 2D).

\section{MiR-4458 targeted IKBKE}

To identify which genes miR-4458 targets, bioinformatic algorithms were applied. We found that miR-4458 could bind 11 genes (Fig. 4A). Of these predicated genes, IKBKE was identified as a breast cancer oncogene [23]. For the importance of $I K B K E$ and our interests, IKBKE was chosen for further study.

To confirm whether miR-4458 could target IKBKE, the putative miR-4458 binding site in 3' UTR IKBKE was mutated (Fig. 4B). A dual luciferase reporter gene assay was performed 


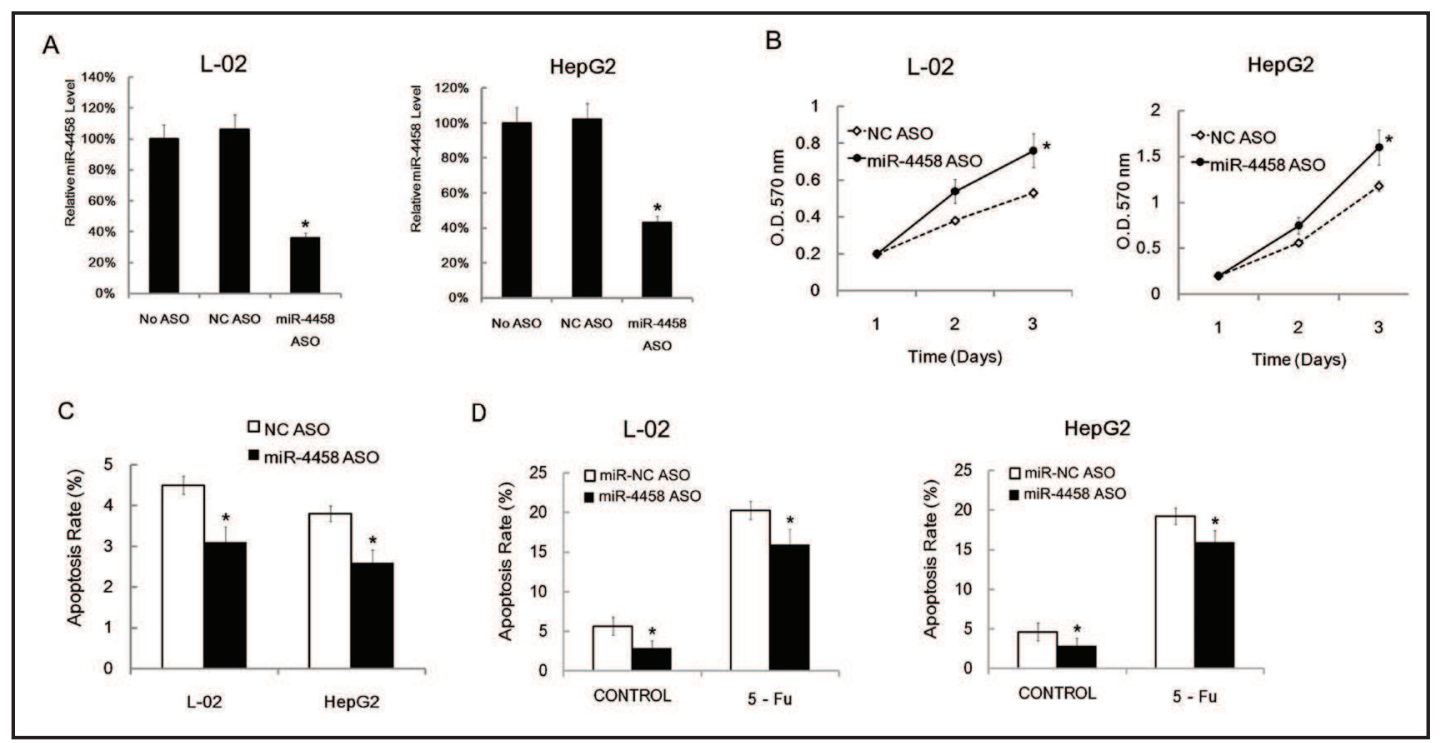

Fig. 3. MiR-4458 ASO promoted L- 02 and HepG2 cells proliferation. A, L-02 and HepG2 cells $\left(5 \times 10^{5}\right.$ cells/ well) were transfected with miR-4458 ASO or control separately. $48 \mathrm{~h}$ or $72 \mathrm{~h}$ later, the miR-4458 expression were assayed by qRT-PCR. Data were normalized to U6 small nuclear RNA. The miR-4458 expression in normal liver tissue were arbitrary defined as $100 \%$. Data are mean \pm SD of three separate independent sample. $\mathrm{B}, 48 \mathrm{~h}$ after the miR-4458 ASO transfection, the cell proliferation were assayed by MTT at the indicted time points (from 1 to 4 hours after transfection). Data are mean \pm SD of three independent sample assays. C, 48 $\mathrm{h}$ after miR-4458 ASO transfection, the cell apoptosis rate of L-02 and HepG2 cells was assayed. D, Following miR-4458 ASO transfection, L-02 and HepG2 cells were treated 5-Fu $(0.5 \mu \mathrm{g} / \mathrm{ml}) .48 \mathrm{~h}$ later, the cell apoptosis rate of L-02 and HepG2 cells was assayed by FACS analysis. Data are mean \pm SD of three separate assays*, $\mathrm{P}<0.05$., $\mathrm{P}<0.05$.

to test whether miR- 4458 could repress the expression of IKBKE. We constructed luciferase reporter plasmids containing wild-type or mutated 3' UTR of IKBKE. We found that miR4458 mimics significantly reduced the luciferase activity of IKBKE reporter with wild-type 3' UTR but had no dramatic effect on the luciferase activity of the IKBKE reporter with mutated 3' UTR(Fig. 4C). Next, we transfected Huh-7 cells with miR-4458 mimics, $48 \mathrm{~h}$ later, the IKBKE protein expression was inhibited (Fig. 4D). Person's correlation coefficient analysis showed that there was an inverse correlation between miR-4458 and IKBKE mRNA in the HCC cell lines and normal lung tissue (Fig. 4E). Thus, our data indicated that miR-4458 inhibited IKBKE expression.

\section{High expression of IKBKE correlated with short overall survival}

To investigate the role of IKBKE expression in HCC, HCC tissue microarray of 222 patients' samples was analyzed. We found that IKBKE protein expression was higher in HCC tissue than in normal liver tissue (Fig. 5A, B). In the figure 5B, we found that IKBKE was significantly increased in 200 of 222 HCC tissues compared with the matched adjacent normal tissues, suggesting that IKBKE may be an important protein associated with the development of HCC. To evaluate the clinical significance of IKBKE overexpression in HCC, we investigated whether the levels of IKBKE expression were associated with overall survival in HCC. 222 HCC patients had been followed-up for 3 years. Kaplan-Meier curves indicated that patients with higher IKBKE expression had a significantly shorter overall survival $(\mathrm{p}<0.05)$ than those with lower IKBKE expression (Fig. 5C). To confirm the effect of $I K B K E$, we transfected IKBKE overexpression plasmid into L-02 and HepG2, and found the colony number of tumor cell was increased (Fig. 5D). Then, we over-expressed the IKBKE after the miR-4458 transfection, we found that $I K B K E$ over-expression increased the cell numbers, and partly reduced the inhibitory effect of miR-4458 in SMMC-7721 and Huh-7(Fig. 5E) Next we down-regulated 


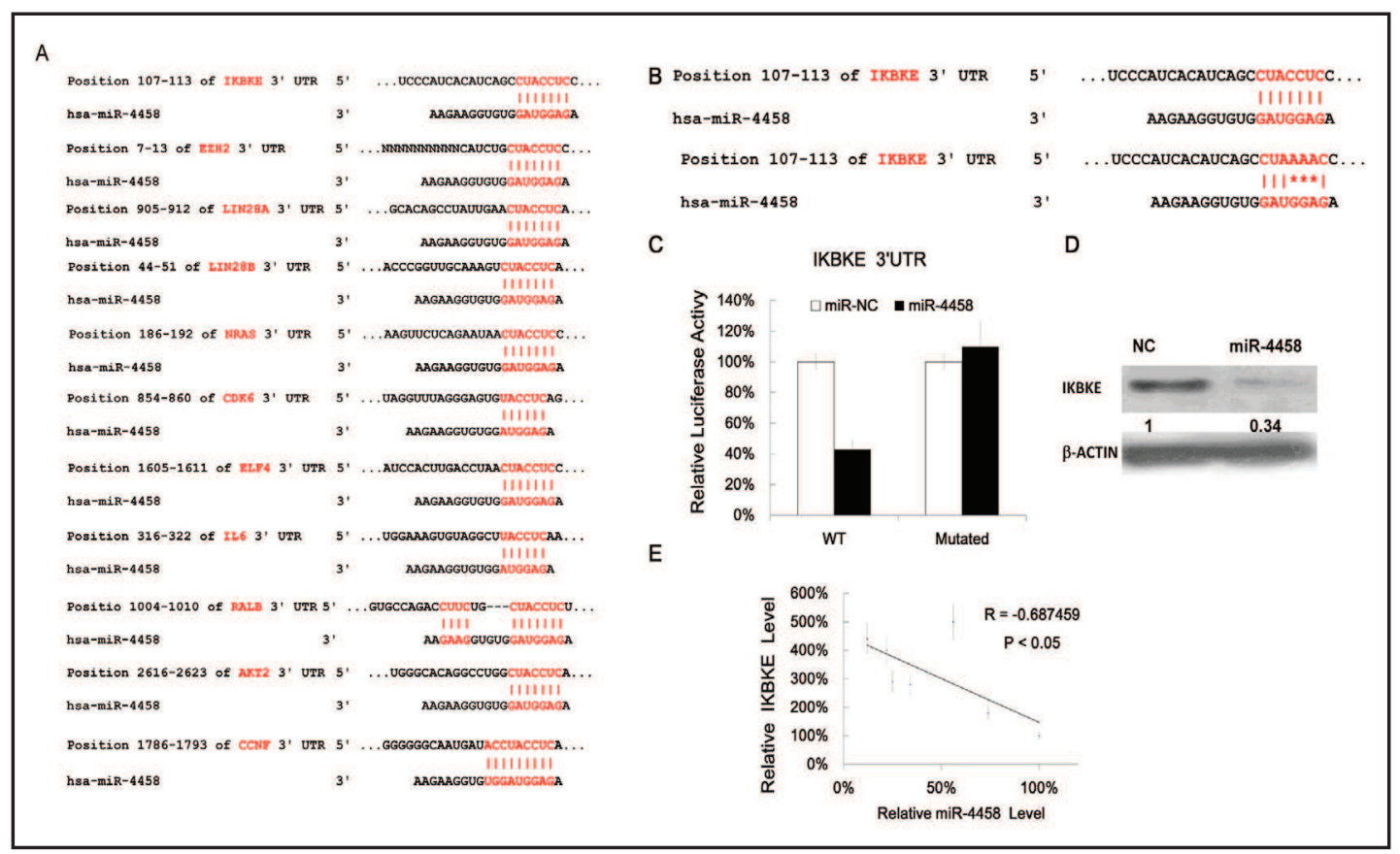

Fig. 4. MiR-4458 targeted IKBKE. A. 11 putative miRNA were predicted by bioinformatic analysis. B. The mutation of IKBKE 3' UTR (miR-4458 binding site). C. Analysis of luciferase activity. Huh7 cells were co-transfected with indicated RNA duplex, pRL-TK, and pMIR-Reporter firely luciferase reporter plasmid containing wild-type or mutant 3' UTR of putative target gene. Firefly luciferase activity was measured and normalized by Renilla luciferase activity $24 \mathrm{~h}$ after transfection. Data are mean \pm SD of separate transfection $(n=6)$ The normalized luciferase activity of NC transfectant in each experiment was set as relative luciferase activity 1. D. the IKBKE protein in Huh7 cells were assayed by Western blot $48 \mathrm{~h}$ after miR- 4458 transfection. E. Inverse correlation between miR-4458 and IKBKE mRNA in the HCC cell lines and normal lung tissue. Data are mean \pm SD of three independent sample assays. *, $\mathrm{P}<0.05$.

the IKBKE expression by si-IKBKE transfection, we found that down-regulation of IKBKE and miR-4458 mimics transfection both decreased the cell numbers (Fig. 5F).

\section{Discussion}

A number of miRNAs has been suggested to play important roles in HCC development [3-22]. Thus, exploring and understanding the more aberrantly expressed miRNAs may help to better reveal the mechanisms underlying HCC carcinogenesis and progression [24]. Here, we identified the role of miR-4458 in HCC, and proved that miR-4458 is a new prognosis predictor for HCC patients and a new potential therapeutic target for HCC. It is very important to identify the molecular markers correlating with the survival of cancer patients. Deregulated expression of both coding genes and miRNAs has been suggested to have considerable potential predicting the prognosis of HCC patients [16]. Previous reports showed that deregulated miR-26 miR-29, miR-199a/b-3p and miR-99a correlated with the survival of HCC $[16,24,42,43]$. Detecting the expression level of these miRNAs, in combination with miR-4458 and other coding genes, may be valuable to predict the prognosis of HCC patients more accurately.

With informatics prediction and sequential experimental demonstration. IKBKE were identified as target of miR-4458 in our study. IKBKE has been identified as a breast cancer oncogene [23]. Our clinical data showed that IKBKE was significantly increased in 200 of 222 HCC tissues compared with the matched adjacent normal tissues, suggesting the importance of IKBKE in the development of HCC. We also demonstrate that higher expression of IKBKE in 

Cellular Physiology Cell Physiol Biochem 2015;35:1797-1807

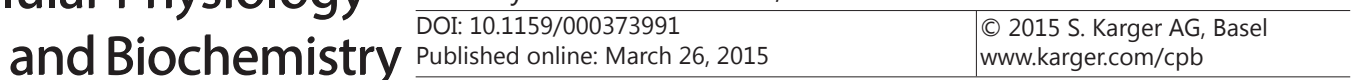
Tang et al.: MiR-4458 on HCC

A

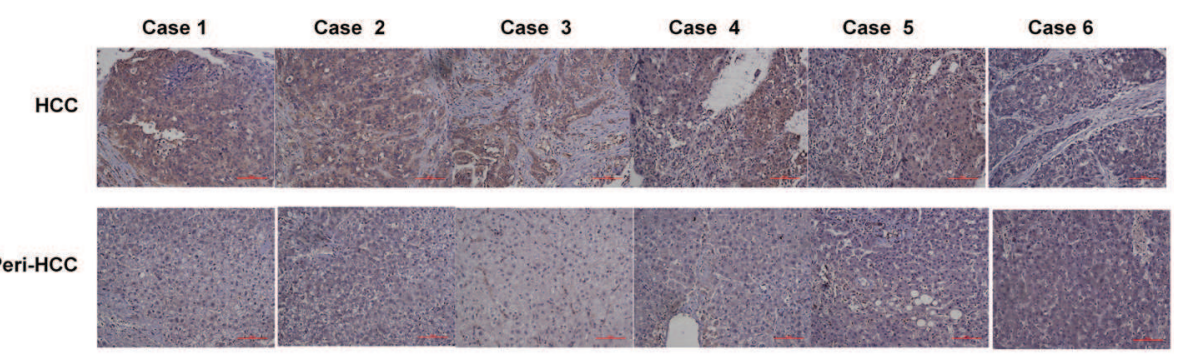

B

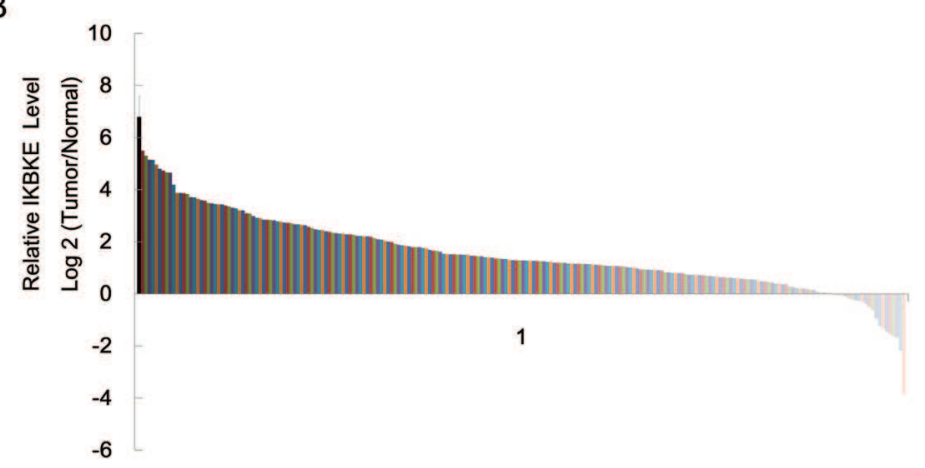

C

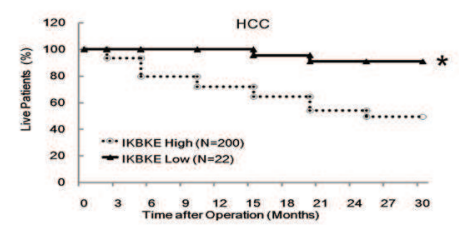

D

E
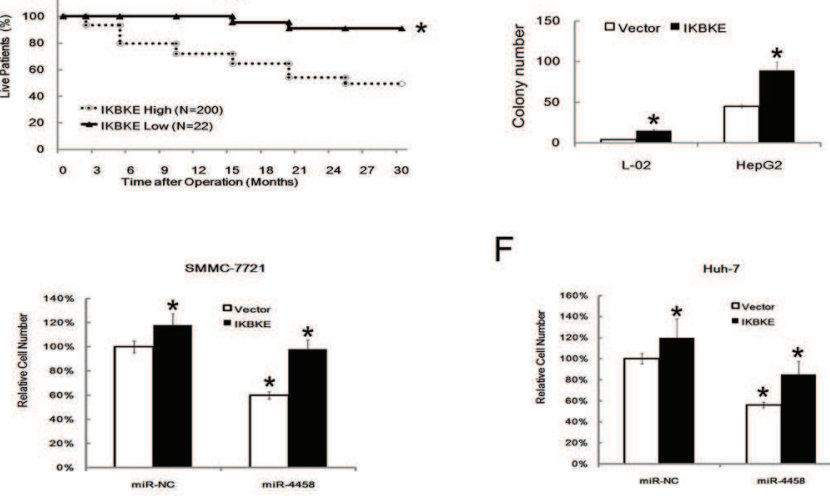

$\mathrm{F}$

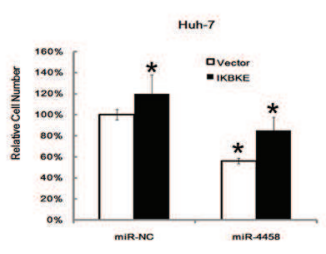

Fig. 5. Higher IKBKE expression level in HCC tissue correlates with worse prognosis of HCC patients. A. Immunohistochemical assay of IKBKE in HCC tissues and matched adjacent normal tissues (Peri-HCC). 6 representative samples were shown. B. IKBKE protein expressed level in tumor were compared with IKBKE protein expressed level in matched adjacent normal tissues $(n=222)$. C. Kaplan-Meier plot of overall survival in HCC patients post-operation according to the immunostaining results of IKBKE. IKBKE median value of all 222 cases was chosen as the cutoff point for separating IKBKE high expression tumors $(n=111)$ from IKBKE low expression cases $(n=111)$. D. 24h after IKBKE overexpression plasmid transfection, the colony

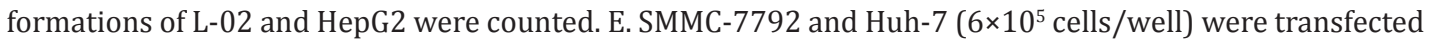
with miR-4458 or miR-NC (NC) separately. $12 \mathrm{~h}$ later, these cell were transfected with empty plasmid, or IKBKE overexpression plasmid. Then the MTT assay were performed. The OD value from MTT assay were presented as the relative cell number. The relative cell number in miR-NC+Vector (negative control) was defined as $100 \%$. NS, not significantly, Data are mean \pm SD of three independent sample assays. F. SMMC7792 and Huh-7 ( $6 \times 10^{5}$ cells/well) were transfected with miR-4458 or miR-NC (NC) separately. $12 \mathrm{~h}$ later, these cell were transfected with si-NC, or si- IKBKE Then the MTT assay were performed. The OD value from MTT assay were presented as the relative cell number. The relative cell number in miR-NC+ Si-NC, (negative control) was defined as $100 \%$. NS, not significantly, Data are mean \pm SD of three independent sample assays. $*, \mathrm{P}<0.05$. 


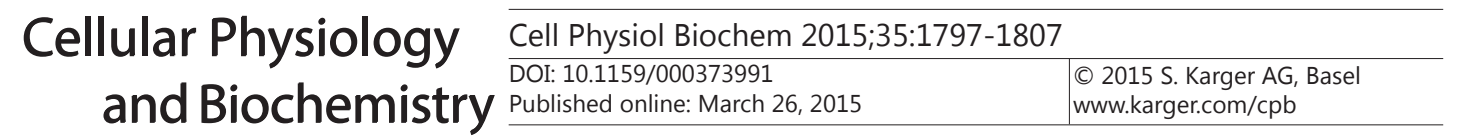

Tang et al.: MiR-4458 on HCC

HCC tissues significantly correlated with shorter survival of HCC patients. Our data indicated that IKBKE protein may be a predicator of prognosis of HCC. Similarly, we proved that high expression of IKBKE led the colony number increased in HCC cell lines as in breast cancer cells [23], indicating that $I K B K E$ may play the similar roles in HCC .

Informatics prediction showed that NRAS and EZH2 are the potential targeted genes of miR-4458. Previous study showed that NRAS are key cancer-related gene in the RAS/RAF signaling pathways which play central roles in carcinogenesis of HCC [44]. EZH2 in HCC could be targeted by miR-26a which inhibits HCC proliferation [45]. Whether miR-4458 plays its role via NRAS and EZH2 needed further investigation.

HCC is the most fatal cancer around the world, especially in China. HCC confers a poor prognosis when diagnosed at advanced stages. The diminished treatment efficacy may be due to multidrug resistance transporter protein and hyper-activated drug-metabolizing pathways. Thus, alternative approaches are urgently needed. Tumor inhibition effect of miR4458 showed in our data indicated the therapy drug possibility of miR-4458. Also, viral and nonviral vectors are being developed by delivery of synthetic RNA to liver [46-48]. Hence, restoration of miR-4458 should have a considerable potential for HCC molecular therapy.

In conclusion, we proved the role of miR-4458 in HCC, and miR-4458 inhibited HCC cell viability via targeting IKBKE. We also highlight IKBKE as a HCC prognosis predictor.

\section{Disclosure Statement}

The authors have declared that no competing interests exist.

\section{Acknowledgements}

We thank Jianhua Yin for providing HCC Survival-base tissue microarray of HCC.

\section{Reference}

1 Jemal A, Siegel R, Ward E, Hao Y, Xu J, Thun MJ: Cancer statistics, 2009. CA Cancer J Clin 2009;59:225-249.

2 Jemal A, Bray F, Center MM, Ferlay J, Ward E, Forman D: Global cancer statistics. CA Cancer J Clin 2011;61:69-90.

3 Ahmed F, Perz JF, Kwong S, Jamison PM, Friedman C, Bell BP: National trends and disparities in the incidence of hepatocellular carcinoma, 1998-2003. Prev Chronic Dis 2008;5:A74.

4 Llovet JM: Updated treatment approach to hepatocellular carcinoma. J Gastroenterol 2005;40:225-235.

-5 El-Serag HB, Rudolph KL: Hepatocellular carcinoma: Epidemiology and molecular carcinogenesis. Gastroenterology 2007;132:2557-2576.

-6 Gramantieri L, Ferracin M, Fornari F, Veronese A, Sabbioni S, Liu CG, Calin GA, Giovannini C, Ferrazzi E, Grazi GL, Croce CM, Bolondi L, Negrini M: Cyclin g1 is a target of mir-122a, a microrna frequently downregulated in human hepatocellular carcinoma. Cancer Res 2007;67:6092-6099.

7 Budhu A, Jia HL, Forgues M, Liu CG, Goldstein D, Lam A, Zanetti KA, Ye QH, Qin LX, Croce CM, Tang ZY, Wang XW: Identification of metastasis-related micrornas in hepatocellular carcinoma. Hepatology 2008;47:897907.

8 Xu T, Zhu Y, Xiong Y, Ge YY, Yun JP, Zhuang SM: Microrna-195 suppresses tumorigenicity and regulates g1/s transition of human hepatocellular carcinoma cells. Hepatology 2009;50:113-121.

-9 Su H, Yang JR, Xu T, Huang J, Xu L, Yuan Y, Zhuang SM: Microrna-101, down-regulated in hepatocellular carcinoma, promotes apoptosis and suppresses tumorigenicity. Cancer Res 2009;69:1135-1142.

10 Murakami Y, Yasuda T, Saigo K, Urashima T, Toyoda H, Okanoue T, Shimotohno K: Comprehensive analysis of microrna expression patterns in hepatocellular carcinoma and non-tumorous tissues. Oncogene 2006;25:2537-2545. 


\section{Cellular Physiology Cell Physiol Biochem 2015;35:1797-1807 \begin{tabular}{l|l|} 
and Biochemistry Publisned oninne: VIrarcn 26, 2015 & $\begin{array}{l}\text { D 2 2015 S. Karger AG, Basel } \\
\text { www.karger.com/cpb }\end{array}$ \\
\hline
\end{tabular}}

Tang et al.: MiR-4458 on HCC

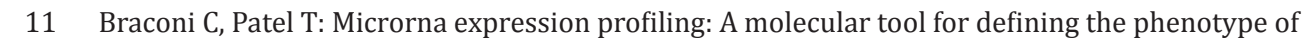
hepatocellular tumors. Hepatology 2008;47:1807-1809.

-12 Murakami Y, Tamori A, Itami S, Tanahashi T, Toyoda H, Tanaka M, Wu W, Brojigin N, Kaneoka Y, Maeda A, Kumada T, Kawada N, Kubo S, Kuroda M: The expression level of mir-18b in hepatocellular carcinoma is associated with the grade of malignancy and prognosis. BMC Cancer 2013;13:99.

13 Gramantieri L, Fornari F, Callegari E, Sabbioni S, Lanza G, Croce CM, Bolondi L, Negrini M: Microrna involvement in hepatocellular carcinoma. J Cell Mol Med 2008;12:2189-2204.

-14 Wang B, Majumder S, Nuovo G, Kutay H, Volinia S, Patel T, Schmittgen TD, Croce C, Ghoshal K, Jacob ST: Role of microrna-155 at early stages of hepatocarcinogenesis induced by choline-deficient and amino aciddefined diet in c57bl/6 mice. Hepatology 2009;50:1152-1161.

15 Coulouarn C, Factor VM, Andersen JB, Durkin ME, Thorgeirsson SS: Loss of mir-122 expression in liver cancer correlates with suppression of the hepatic phenotype and gain of metastatic properties. Oncogene 2009;28:3526-3536.

-16 Ji J, Shi J, Budhu A, Yu Z, Forgues M, Roessler S, Ambs S, Chen Y, Meltzer PS, Croce CM, Qin LX, Man K, Lo CM, Lee J, Ng IO, Fan J, Tang ZY, Sun HC, Wang XW: Microrna expression, survival, and response to interferon in liver cancer. New Engl J Med 2009;361:1437-1447.

-17 Ji J, Yamashita T, Budhu A, Forgues M, Jia HL, Li C, Deng C, Wauthier E, Reid LM, Ye QH, Qin LX, Yang W, Wang HY, Tang ZY, Croce CM, Wang XW: Identification of microrna-181 by genome-wide screening as a critical player in epcam-positive hepatic cancer stem cells. Hepatology 2009;50:472-480.

18 Ladeiro Y, Couchy G, Balabaud C, Bioulac-Sage P, Pelletier L, Rebouissou S, Zucman-Rossi J: Microrna profiling in hepatocellular tumors is associated with clinical features and oncogene/tumor suppressor gene mutations. Hepatology 2008;47:1955-1963.

19 Song G, Sharma AD, Roll GR, Ng R, Lee AY, Blelloch RH, Frandsen NM, Willenbring H: Micrornas control hepatocyte proliferation during liver regeneration. Hepatology 2010;51:1735-1743.

20 Ura S, Honda M, Yamashita T, Ueda T, Takatori H, Nishino R, Sunakozaka H, Sakai Y, Horimoto K, Kaneko $\mathrm{S}$ : Differential microrna expression between hepatitis $\mathrm{b}$ and hepatitis $\mathrm{c}$ leading disease progression to hepatocellular carcinoma. Hepatology 2009;49:1098-1112.

21 Wong TS, Liu XB, Wong BY, Ng RW, Yuen AP, Wei WI: Mature mir-184 as potential oncogenic microrna of squamous cell carcinoma of tongue. Clin Cancer Res 2008;14:2588-2592.

-22 Wang Y, Lee AT, Ma JZ, Wang J, Ren J, Yang Y, Tantoso E, Li KB, Ooi LL, Tan P, Lee CG: Profiling microrna expression in hepatocellular carcinoma reveals microrna-224 up-regulation and apoptosis inhibitor-5 as a microrna-224-specific target. J Biol Chem 2008;283:13205-13215.

-23 Boehm JS, Zhao JJ, Yao J, Kim SY, Firestein R, Dunn IF, Sjostrom SK, Garraway LA, Weremowicz S, Richardson AL, Greulich H, Stewart CJ, Mulvey LA, Shen RR, Ambrogio L, Hirozane-Kishikawa T, Hill DE, Vidal M, Meyerson M, Grenier JK, Hinkle G, Root DE, Roberts TM, Lander ES, Polyak K, Hahn WC: Integrative genomic approaches identify ikbke as a breast cancer oncogene. Cell 2007;129:1065-1079.

24 Li D, Liu X, Lin L, Hou J, Li N, Wang C, Wang P, Zhang Q Zhang P, Zhou W, Wang Z, Ding G, Zhuang SM, Zheng L, Tao W, Cao X: Microrna-99a inhibits hepatocellular carcinoma growth and correlates with prognosis of patients with hepatocellular carcinoma. J Biol Chem 2011;286:36677-36685.

25 John B, Enright AJ, Aravin A, Tuschl T, Sander C, Marks DS: Human microrna targets. PLoS Biol 2004;2:e363.

-26 Krek A, Grun D, Poy MN, Wolf R, Rosenberg L, Epstein EJ, MacMenamin P, da Piedade I, Gunsalus KC, Stoffel M, Rajewsky N: Combinatorial microrna target predictions. Nat Genet 2005;37:495-500.

-27 Ma Q Jiang Q, Pu Q, Zhang X, Yang W, Wang Y, Ye S, Wu S, Zhong G, Ren J, Zhang Y, Liu L, Zhu W: Microrna-143 inhibits migration and invasion of human non-small-cell lung cancer and its relative mechanism. Int J Biol Sci 2013;9:680-692.

28 Zhou BR, Guo XF, Zhang JA, Xu Y, Li W, Wu D, Yin ZQ, Permatasari F, Luo D: Elevated mir-34c-5p mediates dermal fibroblast senescence by ultraviolet irradiation. Int J Biol Sci 2013;9:743-752.

29 Coronnello C, Benos PV: Comir: Combinatorial microrna target prediction tool. Nucleic Acids Res 2013;41:W159-164.

-30 Lewis BP, Shih IH, Jones-Rhoades MW, Bartel DP, Burge CB: Prediction of mammalian microrna targets. Cell 2003;115:787-798.

-31 Megraw M, Sethupathy P, Corda B, Hatzigeorgiou AG: Mirgen: A database for the study of animal microrna genomic organization and function. Nucleic Acids Res 2007;35:D149-155. 


\section{Cellular Physiology Cell Physiol Biochem 2015;35:1797-1807 \begin{tabular}{l|l} 
and Biochemistry Publisned onine: 1vilarch 26, 2015 & $\begin{array}{l}\text { C) 2015 S. Karger AG, Basel } \\
\text { www.karger.com/cpb }\end{array}$ \\
\hline
\end{tabular}}

Tang et al.: MiR-4458 on HCC

-32 Alexiou P, Vergoulis T, Gleditzsch M, Prekas G, Dalamagas T, Megraw M, Grosse I, Sellis T, Hatzigeorgiou AG: Mirgen 2.0: A database of microrna genomic information and regulation. Nucleic Acids Res 2010;38:D137141.

33 Griffiths-Jones S, Saini HK, van Dongen S, Enright AJ: Mirbase: Tools for microrna genomics. Nucleic Acids Res 2008;36:D154-158.

34 Guo JP, Coppola D, Cheng JQ: Ikbke protein activates akt independent of phosphatidylinositol 3-kinase/ pdk1/mtorc2 and the pleckstrin homology domain to sustain malignant transformation. J Biol Chem 2011;286:37389-37398.

- 35 Liu C, Gao F, Li B, Mitchel RE, Liu X, Lin J, Zhao L, Cai J: Tlr4 knockout protects mice from radiation-induced thymic lymphoma by downregulation of il6 and mir-21. Leukemia 2011;25:1516-1519.

-36 Liu C, Zhou C, Gao F, Cai S, Zhang C, Zhao L, Zhao F, Cao F, Lin J, Yang Y, Ni J, Jia J, Wu W, Zhou L, Cui J, Zhang W, Li B, Cai J: Mir-34a in age and tissue related radio-sensitivity and serum mir-34a as a novel indicator of radiation injury. Int J Biol Sci2011;7:221-233.

-37 Liu C, Zhang C, Mitchel RE, Cui J, Lin J, Yang Y, Liu X, Cai J: A critical role of toll-like receptor 4 (tlr4) and its' in vivo ligands in basal radio-resistance. Cell Death Dis 2013;4:e649.

-38 Lu J, Wen M, Huang Y, He X, Wang Y, Wu Q Li Z, Castellanos-Martin A, Abad M, Cruz-Hernandez JJ, Rodriguez CA, Perez-Losada J, Mao JH, Wei G: C2orf40 suppresses breast cancer cell proliferation and invasion through modulating expression of $\mathrm{m}$ phase cell cycle genes. Epigenetics 2013;8:571-583.

-39 Bendoraite A, Knouf EC, Garg KS, Parkin RK, Kroh EM, O'Briant KC, Ventura AP, Godwin AK, Karlan BY, Drescher CW, Urban N, Knudsen BS, Tewari M: Regulation of mir-200 family micrornas and zeb transcription factors in ovarian cancer: Evidence supporting a mesothelial-to-epithelial transition. Gynecol Oncol 2010;116:117-125.

-40 Gregory PA, Bert AG, Paterson EL, Barry SC, Tsykin A, Farshid G, Vadas MA, Khew-Goodall Y, Goodall GJ: The mir-200 family and mir-205 regulate epithelial to mesenchymal transition by targeting zeb1 and sip1. Nat Cell Biol 2008;10:593-601.

41 Yin J, Li N, Han Y, Xue J, Deng Y, Shi J, Guo W, Zhang H, Wang H, Cheng S, Cao G: Effect of antiviral treatment with nucleotide/nucleoside analogs on postoperative prognosis of hepatitis b virus-related hepatocellular carcinoma: A two-stage longitudinal clinical study. Journal of clinical oncology : official journal of the Am Soc Clin Oncol 2013;31:3647-3655.

-42 Xiong Y, Fang JH, Yun JP, Yang J, Zhang Y, Jia WH, Zhuang SM: Effects of microrna-29 on apoptosis, tumorigenicity, and prognosis of hepatocellular carcinoma. Hepatology 2010;51:836-845.

43 Hou J, Lin L, Zhou W, Wang Z, Ding G, Dong Q Qin L, Wu X, Zheng Y, Yang Y, Tian W, Zhang Q, Wang C, Zhang Q Zhuang SM, Zheng L, Liang A, Tao W, Cao X: Identification of mirnomes in human liver and hepatocellular carcinoma reveals mir-199a/b-3p as therapeutic target for hepatocellular carcinoma. Cancer Cell 2011;19:232-243.

-44 Hou W, Liu J, Chen P, Wang H, Ye BC, Qiang F: Mutation analysis of key genes in ras/raf and pi3k/pten pathways in chinese patients with hepatocellular carcinoma. Oncology Lett 2014;8:1249-1254.

45 Wang G, Sun Y, He Y, Ji C, Hu B, Sun Y: Mir-26a promoted by interferon-alpha inhibits hepatocellular carcinoma proliferation and migration by blocking ezh2. Gen Test Mole Biomark 2015;19:30-36.

46 Arbuthnot P, Ely A, Weinberg MS: Hepatic delivery of rna interference activators for therapeutic application. Curr Gene Ther 2009;9:91-103.

47 Nishina K, Unno T, Uno Y, Kubodera T, Kanouchi T, Mizusawa H, Yokota T: Efficient in vivo delivery of sirna to the liver by conjugation of alpha-tocopherol. Mol Ther 2008;16:734-740.

48 Kim SI, Shin D, Choi TH, Lee JC, Cheon GJ, Kim KY, Park M, Kim M: Systemic and specific delivery of small interfering rnas to the liver mediated by apolipoprotein a-i. Mol Ther 2007;15:1145-1152. 